\title{
O papel da afetividade na atuação do professor tutor
}

\author{
Katia Maria Senise Martinho Rabelo, Laurinda Ramalho de Almeida \\ Programa de Estudos Pós-Graduados em Educação Psicologia da Educação, Pontifícia Universidade Católica de São Paulo, Brasil
}

\begin{abstract}
Resumen
A ação de professores tutores tem sido adotada por escolas no Brasil no sentido de favorecer 0 desenvolvimento amplo dos alunos. Além do levantamento documental sobre o que seria a tutoria na literatura espanhola, este trabalho ouviu, por meio de entrevistas semiestruturadas, dois professores dos anos finais do Ensino Fundamental, em duas instituições de ensino particular da cidade de São Paulo. A análise qualitativa permitiu entrecruzar essas atuações aos pressupostos da psicogenética walloniana, que considera a imbricada relação entre as dimensões do indivíduo (conjuntos afetividade, cognição e ato motor) e o papel do meio como constitutivo dos indivíduos. Indicamos que os professores tutores reconhecem que o apoio oferecido a esses alunos qualifica o processo de aprendizagem e os apoiam sobremaneira.

Palabras clave: professor tutor, afetividade, Henri Wallon.
\end{abstract}

Este trabalho, advindo de uma pesquisa para obtenção do título de Mestre em Educação: Psicologia da Educação, propõe uma reflexão sobre o papel de professores tutores nos anos finais do Ensino Fundamental.

A escolha por lançar luzes sobre o fazer do professor tutor nos anos finais do Ensino Fundamental, sujeito que vem surgindo nas escolas do Brasil com o papel de cuidar dos jovens, de suas aprendizagens e da convivência na sala de aula, espaço este considerado um rico, complexo e intenso meio de formação, diz respeito à intensidade das mudanças pelas quais passam os alunos quando transitam entre as séries iniciais e finais do Ensino Fundamental. Vale constar que, de acordo com o sistema educacional brasileiro, as séries são organizadas por dois anos de Educação Infantil, nove anos de Ensino Fundamental e três anos de Ensino Médio.

Uma pesquisa nacional recente, realizada pela Fundação Carlos Chagas e publicada pela Fundação Victor Civita, trouxe à luz questões relevantes sobre as características dos anos finais do Ensino Fundamental. Nesse momento, os componentes curriculares são ministrados por professores especialistas, fragmentando a rotina escolar do aluno entre diversos professores. O estudo ouviu jovens de escolas públicas de dois estados brasileiros, desejando captar o que pensam os alunos na transição dos anos iniciais para os anos finais e as especificidades desse nível de ensino.

Curioso observar que tanto professores quanto alunos identificam que as novas experiências vividas no cotidiano escolar, após a transição do $5^{\circ}$ para o $6^{\circ}$ ano, com maior número de docentes e diferentes estilos de organização social e didática, tornam mais complexa a rotina escolar. Ademais, considerando que após o $6^{\circ}$ ano, cada docente acompanha o aluno apenas na disciplina que ministra, nem sempre existe quem assuma a tarefa de orientar e acompanhar os discentes em suas novas atribuições e normalmente inexistem ações sistemáticas para ajudar os alunos a se adaptarem às novas condições e à transição entre os níveis de ensino. É nesse momento que também a família se vê frente a novos desafios para dar continuidade à formação de seus filhos.

Em contrapartida, devemos também considerar que os desafios não são menores para os docentes nesse nível de ensino. Todas essas diferenças colocam grandes desafios para os docentes, que precisam planejar metodologias e estratégias que atendam e atinjam uma diversidade grande de alunos num mesmo nível de ensino.

Nesse contexto de anos finais do Ensino Fundamental, em meio a transformações, complexidades, aproximações e distanciamentos, a atuação de professores tutores vem sendo adotada em algumas escolas no sentido de buscar alternativas eficazes que oportunizem melhores aprendizagens e desenvolvimento dos alunos.

\section{Os referenciais teóricos}

Embora pouco difundida e estudada no Brasil, a ação de tutoria proposta neste estudo para as escolas brasileiras tem seu embasamento teórico nos referenciais espanhóis advindos da reforma educativa da Espanha após 1990 (LOGSE). A Ley de Ordenación General del Sistema Educativo (LOGSE) determinou a necessidade de as escolas espanholas disporem de professores tutores para seus alunos da escola básica. Nessa experiência, cada turma de alunos possui um tutor que atua individual e coletivamente, a fim de apoiar os estudantes no seu desenvolvimento mais amplo.

Autores como Rodrigues (2002) defendem que "a tutoria deve ser um compromisso de todos os professores, independente de terem ou não esse cargo, da mesma maneira que o conteúdo da tutoria deve impregnar a vida cotidiana da escola”.

Embora essa atribuição possa estar designada ao professor tutor, deve ser uma postura do tutor e dos demais professores, pois valoriza tanto o papel acadêmico como o educativo. É, portanto, inerente à função de professor e, para seu pleno sucesso, demanda o compromisso coletivo dos professores com as aprendizagens dos alunos.

É ainda uma ação que se estende para além da área do conhecimento do professor especialista e pressupõe um olhar para além do papel de instrução.

Assim, considerando a forma como o ensino brasileiro é organizado a partir dos anos finais do 
Ensino Fundamental, de modo geral, a ação tutorial surge como resposta à necessidade, tanto de contrapor à presença de diferentes professores na sala de aula, quanto de materializar o princípio geral da educação, que deve ser de ajuda e orientação para a formação do sujeito integral, indo além do papel de instrução.

\section{Os pressupostos wallonianos}

Analisando o referencial sobre professores tutores existentes na Espanha, identificamos a necessidade de complementar a análise dessa atuação com o recorte da afetividade, segundo os postulados de Henri Wallon (1879-1962).

Ao se decidir pelo referencial teórico da psicogenética walloniana, assume-se que o desenvolvimento da pessoa é um todo imbricado de suas dimensões. Henri Wallon foi um dos principais estudiosos sobre a relação intrínseca entre afetividade e cognição. Analisou a emoção como um fato fisiológico, com seus componentes humorais e motores, e, ao mesmo tempo, como um comportamento social na sua função de adaptação do ser humano ao seu meio. Assim, o conjunto de funções psíquicas, numa imbricada relação dos conjuntos afetivos, motores e cognitivos, constituem a pessoa. Sobre esse conceito Mahoney (2000) acrescenta que cada um dos conjuntos participa da constituição dos outros, funcionando, então, o psiquismo como uma unidade. Devido a essa estreita relação, somente podem ser separados e destacados individualmente para fins didáticos, pois, na realidade concreta, são inseparáveis.

Ademais, a afetividade também assume igual relevância nas relações interpessoais que se estabelecem no espaço escolar, sendo constitutivas das pessoas que ali estão. Essa visão está embasada nos fundamentos da psicogenética de Henri Wallon, psicólogo do desenvolvimento que pôs suas ideias a favor da reforma educativa da França, após a Segunda Guerra Mundial (Plano Langevin-Wallon).

Tal plano entendia a escola como um espaço privilegiado para a formação dos valores éticos e morais, alicerçada pelos princípios de justiça, igualdade e respeito à diversidade, fomentando a autonomia, a cidadania e a orientação profissional. Enfatizava a importância de uma educação que privilegiasse simultaneamente os interesses da comunidade e de seus membros, destacando o "princípio da justiça” como imprescindível para sua concretização (Langevin \& Wallon, 2000). Considerava a escola como espaço social e lócus de construção de valores como solidariedade e justiça.

Para o autor, o desenvolvimento humano também está integrado ao meio em que o sujeito está imerso, e o homem é um ser íntima e essencialmente social. Uma das mais importantes afirmações de Wallon diz respeito à relevância do contexto social na constituição do humano. "É social não em virtude de contingências exteriores, mas em consequência de uma necessidade íntima. Ele o é geneticamente.” (Wallon, 1975, p.159).

Apesar de meio e grupo serem conceitos distintos, por vezes se sobrepõem e se complementam. O meio e o ser vivo são partes integrantes de um todo e suas relações são de dependência e transformações mútuas.

A escola representa, portanto, um importante meio físico e social. Além do espaço que ocupa, como se configura e o que oferece, está mergulhada na cultura do seu tempo. Exerce, assim, influência sobre o desenvolvimento do indivíduo, ao mesmo tempo em que também provoca mudanças nesse meio. Nessa relação recíproca de influências e alterações, professores e alunos que compõem o meio escolar, enquanto interagem, ressignificam-se e constituem-se diariamente.

Nesse contexto, o papel do professor, também um ser biológico-social-cultural, que ao humanizar o outro também se humaniza, deve ser o de oferecer condições para que seus alunos se desenvolvam não somente cognitivamente, mas também nos aspectos afetivo e motor.

\section{Procedimento metodológico: 0 ir e vir na ponte}

O referencial teórico escolhido serviu de fio condutor para as análises das experiências de tutoria e dos estudos realizados na Espanha, para propor uma atuação que pudesse ser lida sob a lente da psicologia genética walloniana, que valoriza a finalidade da atividade educativa como aquela preocupada com o desenvolvimento completo da pessoa e que transcende a mera instrução para promover o desenvolvimento cognitivo, afetivo, social e físico do aluno. Ao considerar o indivíduo um todo indivisível de suas dimensões e a relação organismo-meio como fatores básicos do desenvolvimento, o espaço escolar democrático e comprometido com a aprendizagem de todos demanda articuladores que promovam pontes entre todos os sujeitos.

Esta pesquisa buscou compreender o que seria a atividade de tutoria nos anos finais do Ensino Fundamental e levantou algumas experiências de escolas brasileiras que possuem essa atuação. Também buscou contribuir com a literatura brasileira sobre tutoria ao pesquisar na literatura espanhola alguns pressupostos dessa ação tutorial, uma vez que se dedicou a estudar o que seria a ação de professores tutores na escolarização básica.

A escolha metodológica se baseou em duas etapas: inicialmente, realizar uma pesquisa documental sobre o que seria a ação tutorial nos referenciais teóricos espanhóis e, posteriormente, entrevistar dois professores dos anos finais do Ensino Fundamental em duas escolas particulares da cidade de São Paulo, os quais, além de exercerem a docência em alguma área do conhecimento, também atuam como tutores de seus alunos. A escolha dos entrevistados se deu pela disponibilidade de cada um e de suas escolas em participar da pesquisa.

Optamos por realizar entrevistas semiestruturadas para o levantamento das informações, pois dariam abertura para os entrevistados discorrerem sobre suas experiências e, no diálogo com a pesquisadora, a compreensão sobre a realidade do professor poderia ser mais fielmente apreendida pela entrevistadora. 
Por sua vez, os relatos dos professores entrevistados sobre a própria atuação foram analisados em confronto com os pressupostos wallonianos sobre a relação imbricada dos conjuntos funcionais e o papel do meio na constituição do indivíduo.

Após a transcrição das entrevistas, os relatos foram organizados em quadros segundo metodologia desenvolvida pela pesquisadora e sua orientadora.

Os quadros de análise das entrevistas indicaram, em três colunas: a atribuição dos significados (compreensão que a pesquisadora obteve a partir do relato do entrevistado); o apoio da teoria; e a análise inicial das informações, de forma a possibilitar as análises seguintes.

\section{A análise: proposição para novos rumos}

Muito embora tivéssemos, na proposta inicial, a intenção de entrevistar professores com práticas de tutoria semelhantes, como se trata de um novo sujeito nas instituições escolares brasileiras e de um fazer sem precedentes no ensino formal deste país, deparamo-nos com experiências diferentes de tutoria, o que permitiu o enriquecimento das análises no confronto com o referencial teórico escolhido.

O principal referencial teórico desta pesquisa foi a teoria do desenvolvimento de Henri Wallon. Entre tantas contribuições que esse autor deixou para a Psicologia e a Educação, é destacado aqui o desenvolvimento da pessoa completa como uma relação imbricada de suas dimensões cognitivas, emocionais e motoras, e ainda integrada ao meio em que está imersa, e o homem como um ser íntima e essencialmente social.

Henri Wallon, ao longo de toda a produção científica, defendia que a formação para a cidadania solidária e ética deveria ser um dos pressupostos da educação, o que também foi apresentado nos princípios do Plano Langevin-Wallon.

Assim, ao se entrecruzarem os relatos dos dois professores tutores entrevistados com os referenciais teóricos da psicogenética walloniana, encontraram-se ora aproximações, ora distanciamentos das referidas atuações ao que Wallon dizia ser uma formação ampla e integral.

Assim, além de confrontar as práticas realizadas pelos entrevistados em escolas brasileiras com os pressupostos espanhóis sobre a ação de tutores, este estudo defende ainda que essas ações têm também como referencial a psicologia genética de Henri Wallon.

Inicia-se, portanto, esta análise indicando que se encontra na fala de um dos professores uma das principais preocupações dos pensamentos wallonianos para a educação, ou seja, a orientação dos alunos para a vida em sociedade. $O$ professor 1 relata que sua atuação permite intencionalmente promover a reflexão do jovem sobre seu papel na sociedade:

[...] eu faço sempre um percurso, [...] de sempre permitir uma reflexão de como as ações individuais e coletivas interferem na vivência social. Então, [...] eu tento dialogar e refletir com o aluno para que ele se perceba como cidadão e como a sua situação de cidadão [...] interfere na vivência coletiva [...] [Professor 1].

O fazer escolar é essencialmente coletivo. As situações de aprendizagem demandam um todo articulado de pessoas com a mesma intenção e atitudes coerentes entre si, muito embora se aceite que cada professor, constituído ao longo de uma trajetória pessoal e profissional, pelas memórias afetivas do ser aluno e pelas apropriações simbólicas e culturais vivenciadas, traga as marcas de sua singularidade perante os alunos.

No relato do professor 1, a necessidade de articulação, apoio e entendimento entre os professores para o melhor desempenho das atividades do tutor fica evidente: [...] são realizados encontros e Conselhos entre os professores para que o tutor colha informações e recomendações do conjunto dos professores [...] [Professor 1].

Em sua realidade, os Conselhos de Classe permitem que o aluno seja considerado pelo conjunto de educadores e não sob o olhar de um único professor. Sob a ótica walloniana, o desenvolvimento do aluno e, por conseguinte, seu rendimento escolar, pode ser diferente de um componente curricular para outro, o que não deve ser atribuído somente a uma dificuldade com o conteúdo escolar ou às escolhas metodológicas do docente (cognição), mas que também pode estar relacionado aos vínculos interpessoais entre professor e aluno (afetividade) ou ao contexto social ora vivenciado.

Como articulador entre as áreas do conhecimento e os alunos, foi possível perceber que em ambas as experiências relatadas, o tutor assume o papel de aproximar o coletivo dos professores à realidade do aluno. Quando o professor tutor coloca no grupo de professores as informações colhidas nos momentos das tutorias, suas observações contribuem para que os professores especialistas considerem o aluno por muitos outros aspectos e dimensões que anteriormente não haviam sido considerados. Passa a ser uma fala que, além de ser legitimada pelo grupo, é tratada como valiosa por trazer subsídios para se entender o aluno mais amplamente.

Essa articulação entre os professores, que demanda ampliação do olhar de cada um dos docentes para além de seu próprio componente curricular, é favorecida pela ponte estabelecida entre a atividade do tutor e o grupo de professores.

[...] Dentro de várias condições que a gente pode elencar na condição de tutor, tem a condição de servir de um link, de uma espécie de ponte com os professores. E você pode criar essas ferramentas que melhoram a aprendizagem [...] (Professor 2).

Porém, esse professor relata que essa articulação ainda é um desafio em sua escola: [...] o desafio (é) você trazer aqueles professores que não são tutores daquela turma em específico para alimentar um diagnóstico mais fidedigno do que é o aluno [...]. (Professor 2).

Na série de transição, do $5^{\circ}$ para o $6^{\circ}$ ano, fica ainda mais evidente a necessidade da articulação entre os 
docentes. Como já apresentado, o estudo da Fundação Carlos Chagas (2012) ressalta que muitas são as críticas à fragmentação observada no tratamento das disciplinas nos anos finais, o que dificulta essa transição. Como cada docente acompanha o aluno apenas na disciplina que ministra, as demandas dirigidas aos estudantes acabam sendo pouco planejadas e raramente articuladas.

$\mathrm{O}$ referido estudo ainda indica que após o $6^{\circ}$ ano, nem sempre existe quem assuma a tarefa de orientar e acompanhar os discentes em suas novas atribuições. O professor 2 salienta a necessidade de orientação aos alunos que chegam aos anos finais do Ensino Fundamental:

[...] Tem vários alunos que chegam aqui no Fundamental II e eles ficam desesperados porque quando recebem a convocação para a tutoria, acham que ou é um castigo, ou que vai durar até o fim do ano [...] (Professor 2).

Sobre a organização pessoal necessária ao bom desempenho do aluno, repousa uma importante tarefa do professor tutor. O relato do professor 1 corrobora a necessidade da intervenção do professor tutor para auxiliar os alunos:

[...] Então, ensinar mecanismos de organização referente a registro de aula, a registro de nota nos locais devidos, na agenda, a registro de tarefas de casa para que haja uma realização adequada, [...] porque acredita-se que o registro é ferramenta chave para que o aluno tenha condições de fazer alguma coisa (Professor 1).

No relato seguinte, vemos como a questão da organização tem sido um dilema para a condução da escolarização da contemporaneidade:

[...] E tudo isso se desdobra em sala de aula. Como o menino não tem regras dentro de casa, organização, portanto, vai dormir altas horas, chega na sala de aula, ele tem que dormir. Em algum lugar ele dorme, então, no caso, é na sala de aula. É um menino. Como não tem em casa ninguém que fiscalize, chega em sala de aula. Ele não traz a tarefa [...] (Professor 1).

A proximidade entre professor e aluno proporcionada pela ação de tutoria favorece que o professor veja esse aluno sob vários aspectos. Segundo a psicogenética walloniana, o aluno não é somente a sua dimensão cognitiva.

Muitas vezes entendido como "psicólogo das emoções”, embora fosse psicólogo da integração, Wallon valorizava a integração entre os conjuntos funcionais De forma imbricada, as dimensões afetivas, cognitivas e motoras se interdependem e essa interação funcional confere à pessoa um jeito de existir e atuar próprio, em cada etapa do desenvolvimento.

Se a emoção é contagiosa e a relação professor-aluno é uma relação essencialmente social e humana, é possível compreender que essa relação professor-aluno promova a sensibilização do docente. É o que aparece no relato do professor 1: [...] "e é legal dessa escola fazer isso. Permitiu uma condição de sensibilidade. A instituição abandona a condição de instituição e lida com o ser humano"[...]. Isso mostra que ao professor tutor é permitido transitar pelas emoções dos alunos para melhor compreendê-los.

Podemos perceber que o professor 1 valoriza os encontros individuais como forma de aproximação com o aluno e como possibilidade de compreendê-lo amplamente:

[...] Então, quando você tem esse trato de aproximação com o aluno, você consegue se tornar mais sensível e até se tornar mais tolerante com algumas questões [...] Então, ao invés de tomar, talvez tomar uma medida mais enérgica que cria um distanciamento, a sua sensibilidade aproxima com o aluno e cria ferramentas de facilidade [...] (Professor 1).

A forma como o currículo escolar está organizado pelas disciplinas, a dinâmica das aulas e a organização dos tempos e espaços fazem com que alguns alunos, infelizmente, passem despercebidos aos olhos dos professores nos anos finais do Ensino Fundamental. Não é raro um aluno frequentar muitos anos a mesma escola e os professores pouco o conhecerem. Normalmente, são aqueles que não chamam a atenção ou que não demandam intervenção. A fala do professor 2 confirma essa ideia:

[...] Tem muito aluno que passa na sala de aula um pouquinho invisível. Numa sala de aula que você vai tocando, passa mesmo. Eu não consigo saber por que ele não entendeu. Então me dá um pouquinho mais de clareza quando eu tô num grupo menor [...] (Professor 2).

Ademais, a tutoria favorece que todos sejam observados e orientados, uma vez que implica uma atuação individual, e não somente coletiva. O professor tutor tem a incumbência de organizar atendimentos individuais com seus alunos, acreditando que todos estão em formação e podem se beneficiar da orientação do professor.

\section{Conclusões: a beleza da ponte}

Atualmente as políticas educacionais de diversos países têm levantado discussões sobre o trabalho conjunto das habilidades cognitivas e socioemocionais (também chamadas de habilidades não cognitivas). Em contraponto, a psicogenética walloniana, que sempre empregou esforços para compreender a imbricada relação das dimensões da pessoa, reitera a visão integradora de afetividade, cognição e desenvolvimento motor.

Segundo Henri Wallon, o desenvolvimento cognitivo da pessoa está intimamente ligado ao desenvolvimento emocional, assim como o sujeito estará emocionalmente mais equilibrado se estiver atendido em suas demandas cognitivas e em pleno aprendizado do que lhe é proposto. É destacado aqui que existe uma relação íntima e imbricada das dimensões cognitivas, emocionais e motoras, e ainda, que seu desenvolvimento está integrado ao meio em que está imerso por ser o homem um ser íntima e essencialmente social.

Assim sendo, o avanço a que esta pesquisa se propõe, e sua relevância social, é o de agregar, ao que 
já existe fundamentado sobre a atuação de tutores, os postulados da psiconegética walloniana em defesa de que o indivíduo não pode ser considerado fragmentadamente.

As análises permitiram identificar como a psicologia genética walloniana é valiosa para a compreensão dessa atuação, e também como pode orientar os professores para a promoção de uma educação mais solidária. Foi possível perceber também que o apoio oferecido pelos professores tutores aos alunos nos anos finais do Ensino Fundamental, num momento em que estão vivendo grandes transformações cognitivas, físicas e emocionais, pode qualificar o processo de aprendizagem dos alunos e apoiá-los sobremaneira.

É fundamental também que o professor seja conhecedor do estágio de desenvolvimento em que o jovem está, e que entenda esse sujeito a partir das relações que estabelece no meio escolar e que o afetam.

Outrossim, pelo fato de o sistema educacional brasileiro não propor a figura de professores tutores para as escolas da educação básica, as instituições educacionais que implantaram essa ação encontram algumas dificuldades que ficaram evidentes nos relatos dos entrevistados. As duas primeiras dificuldades estão pautadas na inexistência de parâmetros brasileiros para essa ação e no difícil acesso à bibliografia e referenciais que, por conseguinte, impactam no não embasamento para a prática dos docentes. Pelo fato de essa ação não existir formalmente no sistema educacional brasileiro, as escolas precisaram investir, por si só, tanto na definição da ação quanto na formação em serviço dos seus professores.

Urge, portanto, propor novos estudos que auxiliem na reflexão sobre essa ação, nos benefícios, impactos, complexidade e amplitude, uma vez que já está presente em instituições de ensino no Brasil, mas que ainda não conta com referenciais teóricos nacionais que a fundamentem. Ao salientar os benefícios da ação de professores tutores para a educação nacional, este estudo propõe a presença de tutores, principalmente nos anos finais do Ensino Fundamental.

É necessário olharmos para o forte componente humano e solidário contido na educação e na sua responsabilidade para a formação de toda a sociedade.

Assim, a psicogenética walloniana oferece pistas relevantes para os professores compreenderem o desenvolvimento mais amplo de seus alunos e priorizarem uma formação de cultural geral. Compreendendo-se como importantes mediadores nesse processo, os professores podem atuar como "pontes" por onde transitarão os sonhos, os desejos, as certezas e incertezas de seus alunos, no movimento incessante do vaivém do aprender.

\section{Referências}

Almeida, L.R. (2010). Henri Wallon: Psicólogo do Desenvolvimento. Revista Educação. História da Pedagogia. São Paulo: Editora Segmento, vol. 3, out. , (2012). Contribuição de Henri Wallon para o trabalho do coordenador pedagógico. En: Placco, V.M.S. \& Almeida, L.R. (Orgs). O coordenador pedagógico: provocações e possibilidades de atuação. São Paulo: Edições Loyola.

Arguis, R (et. al.) (2002). Tutoria: com a palavra, o aluno. Porto Alegre: Artmed Editora.

Boza Carreño, A. (et. al.) (2005). Ser professor, ser tutor. Orientación educativa para docentes. Espanha: Hérgue Editorial, $2^{a}$ edição.

Espanha. (1990). Ministerio de Educación y Ciência. Ley Orgánica de Ordenación General del Sistema Educativo, LOGSE. Madrid: BOE, n. 238.

Espanha. (1992). Ministerio De Educación y Ciencia. Orientación y Tutoría. Madrid.

Fundação Carlos Chagas. (2012). Anos Finais de Ensino Fundamental: aproximando-se da configuração atual. En: Estudos e Pesquisas Educacionais. n. 3. São Paulo: Fundação Victor Civita.

Mahoney, A.A. (2000). Introdução. En: Mahoney, A.A. \& Almeida, L.R. (Org.). Henri Wallon: psicologia e educação. São Paulo: Loyola.

Rodriguez, F.L. (2002). Introdução. En: Arguis, R. (et. al.) Tutoria: com a palavra, o aluno. Porto Alegre: Artmed Editora.

Wallon, H. (1979). Psicologia e educação da criança. Lisboa: Editorial Vega.

Plano de Reforma Langevin-Wallon. (1977). En: Merani, A.L. (Ed.). Psicologia $e$ Pedagogia (as ideias pedagógicas de Henri Wallon). Tradução de L. de Almeida Campos. Lisboa: Editorial Notícias. 